\title{
Efeito da Fertilização Amoniacal na Aclimatação de Ingá Sob Alta e Moderada Irradiância
}

\author{
Ana Maria Silva dos Santos ${ }^{1}$, Marciel José Ferreira ${ }^{2}$, \\ José Francisco de Carvalho Gonçalves ${ }^{1}$, Gilberto Costa Justino ${ }^{3}$
}

${ }^{1}$ Coordenação de Dinâmica Ambiental, Instituto Nacional de Pesquisas da Amazônia - INPA, Manaus/AM, Brasil ${ }^{2}$ Departamento de Ciências Florestais, Universidade Federal do Amazonas - UFAM, Manaus/AM, Brasil ${ }^{3}$ Instituto de Ciências Biológicas e da Saúde, Universidade Federal de Alagoas - UFAL, Maceió/AL, Brasil

\begin{abstract}
RESUMO
O nitrogênio pode ser determinante para a tolerância das plantas a fatores de estresse como a alta irradiância. O objetivo deste trabalho foi investigar o efeito da fertilização amoniacal na aclimatação de plantas jovens de ingá sob dois ambientes de luz. O acúmulo e partição de matéria seca, o crescimento, a capacidade fotossintética e os teores foliares de nitrogênio $(\mathrm{N})$ foram analisados em plantas submetidas a irradiância moderada $=554,4 \pm 81 \mu \mathrm{mol} \mathrm{de} \mathrm{fótons} \mathrm{m}^{-2} \mathrm{~s}^{-1} \mathrm{e}$ alta irradiância $=1941 \pm 12,3 \mu \mathrm{mol}$ de fótons $\mathrm{m}^{-2} \mathrm{~s}^{-1}$. Os maiores valores de matéria seca, crescimento e fotossíntese foram verificados em plantas sob moderada e alta irradiância fertilizadas com amônio. A área foliar específica foi maior nas plantas sob moderada irradiância, enquanto que os tratamentos controle e com a participação do $\mathrm{N}$ não diferiram entre si, independentemente do ambiente de luz. A fertilização amoniacal contribuiu para a aclimatação e promoveu o acúmulo de massa seca dos ingás sob moderada e alta irradiância, enquanto plantas crescendo sob moderada irradiância investiram em estratégias de interceptação de energia (e.g., área foliar específica).
\end{abstract}

Palavras-chave: Inga edulis, Fabaceae arbórea, nitrogênio, crescimento, luz.

\section{Effect of Ammonium Fertilization on Acclimation of Ingá to High and Moderate Irradiance}

\begin{abstract}
Nitrogen can be decisive for the tolerance of plants to stress factors such as high irradiance. This work aimed to investigate the effect of ammonium fertilization during acclimation of young ingá plants under two light environments. Accumulation and partitioning of dry matter, growth, photosynthetic capacity and leaf nitrogen content were analyzed in ingá plants subjected to moderate and high irradiance of $554.4 \pm 81 \mu \mathrm{mol}$ photons $\mathrm{m}^{-2} \mathrm{~s}^{-1}$ and $1941 \pm 12.3 \mu \mathrm{mol}$ photons $\mathrm{m}^{-2} \mathrm{~s}^{-1}$, respectively. The highest values of dry matter, growth and photosynthesis were observed in plants subjected to moderate and high irradiance fertilized with ammonium. The specific leaf area was higher in plants under moderate irradiance, while the treatments control and $\mathrm{N}$ fertilization showed no differences, independent of light condition. The ammonium fertilization contributed to acclimation and dry matter accumulation of ingá under moderate and high irradiance, while plants subjected to moderate irradiance invested in strategies for energy interception (e.g. specific leaf area).
\end{abstract}

Keywords: Inga edulis, leguminous tree species, nitrogen, growth, light. 


\section{INTRODUÇÃO}

As estratégias de aclimatação das espécies, ou mesmo das folhas da mesma espécie, às condições contrastantes de irradiância são fundamentais para a sobrevivência, crescimento e desenvolvimento das plantas em determinados ambientes, além de ter implicações importantes no manejo delas em condições de plantio (Larbi et al., 2015; Scoffoni et al., 2015). De maneira geral, as espécies alteram parâmetros estruturais e funcionais conforme o ambiente de luz em que estão crescendo (Tripathi \& Raghubanshi, 2014). Em alta irradiância (pleno sol) ocorrem alterações na partição de biomassa, como exemplo, maior razão raiz:parte aérea, redução em área foliar específica, maior proporção de carotenóides e da razão clorofila $a$ : clorofila $b$, maior eficiência no uso do nitrogênio e assimilação de $\mathrm{CO}_{2}$ (Coste et al., 2010; Ferreira et al., 2013; Tripathi \& Raghubanshi, 2014; Costa et al., 2015). Em situação oposta, a condição de moderada irradiância pode promover o aumento da eficiência na captação de luz, devido ao maior investimento em área foliar, teor de pigmentos cloroplastídicos por unidade de massa foliar e tamanho e número dos complexos coletores de luz (LHCII) (Sarijeva et al., 2007; Rooijen et al., 2015). A interação nitrogênio-alta irradiância reflete o papel fundamental que esse nutriente desempenha no processo fotossintético, uma vez que o status de nitrogênio foliar pode ser decisivo para a maior eficiência no uso da energia e, consequentemente, diminuição do potencial de fotoinibição (Salomon et al., 2013).

Nas plantas, o nitrogênio $(\mathrm{N})$ tem como maior dreno metabólico o processo de fotossíntese: cerca da metade do total de $\mathrm{N}$ foliar é utilizado nas atividades do metabolismo fotossintético (Onoda et al., 2004; Santiago et al., 2013). No aparato fotossintético, parte do $\mathrm{N}$ é destinado à fase fotoquímica da fotossíntese, a exemplo da síntese de clorofilas presentes nos sistemas coletores de luz, os complexos antenas, e nas estruturas das proteínas transportadoras de elétrons (Eichelmann et al., 2005; Salomon et al., 2013). Ademais, na fase bioquímica da fotossíntese, o nitrogênio é constituinte das proteínas/enzimas do ciclo de Calvin, em particular a rubisco (ribulose-1,5-bisfosfato carboxilase/oxigenase), que representa cerca de $40 \%$ das proteínas solúveis nas folhas, sendo responsável pela incorporação do $\mathrm{CO}_{2}$ ao substrato ribulose-1,5-bisfosfato (Eichelmann et al., 2005; Salomon et al., 2013). Todavia, existem também registros na literatura sobre outros drenos de $\mathrm{N}$ que podem, inclusive, mudar a alocação de $\mathrm{N}$ foliar, $\mathrm{e}$ essa possível troca de dreno, que constitui diferente alocação de $\mathrm{N}$ da fotossíntese para outra demanda celular (e.g., parede celular a partir da estruturação de proteínas de defesa), sugere que as plantas, ao mudarem a alocação de $\mathrm{N}$, podem aumentar a taxa ou duração de assimilação de carbono, maximizando o seu desempenho em ambientes que apresentem variações nos fatores abióticos (Lambers \& Poorter, 1992; Onoda et al., 2004).

A fertilização nitrogenada pode ser determinante para a melhor aclimatação de plantas expostas à alta irradiância (Ramalho et al., 2000). Em particular, o efeito positivo do amônio em plantas submetidas a essa condição tem sido atribuído à maior densidade de fluxos fotossintéticos, que favorece a biossíntese de carboidratos, os quais são translocados para a raiz (Ariz et al., 2011), aumentando as taxas de assimilação do amônio, haja vista que a assimilação desse íon a aminoácidos e proteínas requer disponibilidade de carbono, fornecido pelo ciclo dos ácidos tricarboxílicos (TCA) (Ariz et al., 2013; Setién et al., 2013).

As respostas das espécies arbóreas cultivadas sob fertilização nitrogenada em diferentes condições de luz têm sido investigadas (Tripathi \& Raghubanshi, 2014). Entretanto, estudos com espécies arbóreas nativas da região amazônica sob tais condições necessitam ser realizados, uma vez que esses dois fatores físicos do ambiente de crescimento das plantas (luz e $\mathrm{N}$-amoniacal) ocorrem em grandes proporções nos biomas tropicais sob cobertura florestal, a exemplo da Amazônia, e, do ponto de vista aplicado, com ênfase em plantios, o crescimento e estabelecimento das mudas no campo dependem sobremaneira desses fatores. Na região amazônica, a espécie Inga edulis Mart. é considerada importante fixadora de nitrogênio (Leblanc et al., 2005). Essa característica é fundamental devido à produção de biomassa foliar rica em nitrogênio, além de favorecer a ciclagem de nutrientes e permitir a recuperação da fertilidade dos solos (Nichols \& Carpenter, 2006). Diante desses benefícios, somados a seu rápido crescimento e ao estabelecimento em solos ácidos, a espécie possui alto potencial para a utilização em programas de reflorestamento sobre áreas degradadas (Hoch et al., 2009; Lojka et al., 2012). Adicionalmente, recentes estudos têm demonstrado que essa espécie é bastante responsiva, em termos de fixação biológica 
de nitrogênio (FBN), fotossíntese e crescimento, à presença de $\mathrm{N}$ inorgânico na forma amoniacal (Omena-Garcia et al., 2011, 2015).

O melhor entendimento das características ecofisiológicas acerca do desempenho das espécies sob condições adversas como baixa disponibilidade de nutrientes no solo e exposição a alta irradiância é fundamental, uma vez que essas informações podem contribuir para o aprimoramento de práticas silviculturais que permitam o melhor crescimento dessas espécies durante a fase inicial de estabelecimento em campo (Campoe et al., 2014).

Neste estudo buscou-se responder a seguinte questão principal: qual a magnitude do efeito da fertilização com amônio sobre os processos de captação e uso da energia luminosa e no ganho de carbono em plantas jovens de $I$. edulis expostas a irradiação moderada e alta irradiância? A hipótese testada é que a fertilização com amônio é determinante para a maior tolerância de plantas jovens de I. edulis ao estresse por irradiação moderada e alta irradiância, promovendo melhor desempenho fotossintético (eficiência na captação e uso da energia e assimilação de carbono) e o crescimento das plantas. Portanto, o objetivo desta pesquisa foi investigar o efeito da fertilização nitrogenada (amônio) no crescimento e características fotossintéticas de plantas jovens de $I$. edulis durante aclimatação a condições contrastantes de irradiância.

\section{MATERIAL E MÉTODOS}

O estudo foi realizado no Instituto Nacional de Pesquisas da Amazônia - INPA-MCTI, Campus III ( $3^{\circ} 5^{\prime} 30^{\prime \prime}$ S e 5959’36” W). As sementes utilizadas no experimento foram obtidas de matrizes cultivadas na Estação Experimental de Silvicultura Tropical do INPA, em Manaus ( $2^{\circ} 47^{\prime} 5^{\prime \prime} \mathrm{S}$ e $\left.60^{\circ} 11^{\prime} 51^{\prime \prime} \mathrm{W}\right)$. As sementes de $I$. edulis germinaram sobre substrato constituído de areia lavada e peneirada em condições naturais. Após 25 dias, quando as plântulas tinham altura e diâmetro médios de $17 \mathrm{~cm}$ e 2,4 mm, respectivamente, $\mathrm{e}$ 2 a 4 folhas, foram transferidas para sacos de polietileno de $4 \mathrm{~kg}$ contendo vermiculita como substrato.

As plantas foram inoculadas duas vezes com $5 \mathrm{~mL}$ de um coquetel contendo bactérias extraídas dos nódulos de nove espécies de leguminosas arbóreas da Amazônia. O intervalo entre as inoculações foi de 15 dias. O meio líquido YM (Yeast Mannitol) foi preparado com a dissolução de $0,2 \mathrm{~g}$ de $\mathrm{MgSO}_{4} \cdot 7 \mathrm{H}_{2} \mathrm{O}$, 0,1 g de $\mathrm{NaCl}, 0,4 \mathrm{~g}$ de $\mathrm{KH}_{2} \mathrm{PO}_{4}, 0,1 \mathrm{~g}$ de $\mathrm{K}_{2} \mathrm{HPO}_{4}, 0,4 \mathrm{~g}$ de extrato de levedura e $10 \mathrm{~g}$ de manitol em $1 \mathrm{~L}$ de água destilada. $\mathrm{O}$ pH foi aferido para 6,5. O meio YM foi distribuído em erlenmeyers de $125 \mathrm{~mL}$, em seguida foram autoclavados por 40 minutos à pressão de $1 \mathrm{kgf} / \mathrm{cm}^{2} \mathrm{e}$ temperatura de $120^{\circ} \mathrm{C}$. Após a autoclavagem, as bactérias foram repicadas e permaneceram em agitador por 2-3 semanas até o crescimento e multiplicação das bactérias, indicado quando o meio tornou-se turvo. $\mathrm{O}$ coquetel de bactérias foi formado pela mistura dos meios de todos os erlenmeyers de $125 \mathrm{~mL}$ em um erlenmeyer de 1 L (Vincent, 1970).

As plantas foram cultivadas em condições de viveiro na Coordenação de Dinâmica Ambiental (CDAM)/Laboratório de Fisiologia e Bioquímica Vegetal do INPA durante 77 dias, sob ambientes de alta irradiância - pleno sol $(1941 \pm 12,3 \mu \mathrm{mol}$ de fótons $\left.\mathrm{m}^{-2} \mathrm{~s}^{-1}\right)$ e irradiância moderada - cobertura de sombrite $\left(554,4 \pm 81 \mu \mathrm{mol}\right.$ de fótons $\left.\mathrm{m}^{-2} \mathrm{~s}^{-1}\right)$. Os valores de irradiância foram obtidos com o sensor óptico de radiação PAR do analisador de trocas gasosas (IRGA) entre as 08:00 e as 12:00 horas. Duas vezes por semana foram aplicados $200 \mathrm{~mL}$ de solução nutritiva modificada de Hoagland \& Arnon (1950), de acordo com os seguintes tratamentos de fertilização: C = controle, sem inoculação e não fertilizadas com amônio; I = inoculadas e não fertilizadas com amônio; $\mathbf{I}+\mathbf{N H}_{4}{ }^{+}=$inoculadas e fertilizadas com amônio (5 mM); $\mathbf{N H}_{4}^{+}=$não inoculadas e fertilizadas com amônio (5 mM).

O crescimento das plantas de I. edulis foi monitorado, semanalmente, por meio de análises de altura com o auxílio de régua milimetrada, considerando a região do coleto até a gema apical, e o diâmetro do caule à altura do coleto, com paquímetro digital. As taxas de crescimento relativo em altura (TCR-a) e diâmetro (TCR-d) e o índice de ganho foliar (IGF) foram calculados conforme Bugbee (1996) e Davanso et al. (2002). Ao final do experimento, folhas, caules, raízes e nódulos foram secos em estufa na temperatura de $65^{\circ} \mathrm{C}$ durante $72 \mathrm{~h}$, até obtenção de massa seca constante.

A área foliar específica (AFE) foi determinada no fim do experimento, a partir de 10 discos foliares de área conhecida $\left(0,283 \mathrm{~cm}^{2}\right)$, acondicionados em sacos de papel e submetidos à secagem em estufa a $70^{\circ} \mathrm{C}$ por 
72 h. A AFE foi determinada como a razão da área foliar $\left(\mathrm{cm}^{2}\right)$ pela massa foliar seca (g) (Evans \& Poorter, 2001).

Os teores foliares de nitrogênio foram obtidos em amostras secas em estufa a $65^{\circ} \mathrm{C}$ e trituradas até a obtenção de um material finamente pulverizado, do qual foi retirado $0,1 \mathrm{~g}$, submetido à pré-digestão e, posteriormente, à digestão com duplo ácido $\left(\mathrm{H}_{2} \mathrm{O}_{2}+\mathrm{H}_{2} \mathrm{SO}_{4}\right)$, com aumento gradativo da temperatura até $350^{\circ} \mathrm{C}$ (Miyazawa et al., 1999). O nitrogênio total foi determinado de acordo com o método de Kjeldahl a partir de uma alíquota de $25 \mathrm{~mL}$ do extrato puro (Bremner, 1996).

As taxas fotossintéticas $\left(\mathrm{P}_{\mathrm{N}}\right)$ foram determinadas em folhas completamente expandidas e em estado fitossanitário adequado. As coletas foram realizadas no período das 08:00 às 12:00 horas por meio de um analisador de gás a infravermelho (IRGA), modelo LI-6400, configurado para densidade de fluxo de fótons (PPFD) saturante de $1.000 \mu \mathrm{mol} \mathrm{m}{ }^{-2} \mathrm{~s}^{-1}$, com a câmara foliar ajustada sob concentração de $\mathrm{CO}_{2}$ de $400 \mu \mathrm{mol} \mathrm{mol}{ }^{-1}$, temperatura de $31^{\circ} \mathrm{C} \pm 1{ }^{\circ} \mathrm{C}$ e vapor de $\mathrm{H}_{2} \mathrm{O}$ de $21 \pm 1 \mathrm{mmol} \mathrm{mol}^{-1}$.

As análises de fluorescência da clorofila $a$ foram realizadas com um fluorômetro portátil entre 08:00 e 12:00 horas, em folhas completamente expandidas e aclimatadas ao escuro por 30 minutos. Em seguida, as folhas foram expostas a um pulso de luz saturante de intensidade de $3.000 \mu \mathrm{mol} \mathrm{m} \mathrm{m}^{-2} \mathrm{~s}^{-1}$ durante $1 \mathrm{~s}$ (Gonçalves et al., 2007). Com base nas análises do teste JIP foram obtidos os parâmetros de rendimento quântico máximo do PSII $\left(\mathrm{F}_{\mathrm{v}} / \mathrm{F}_{\mathrm{m}}\right)$ e o índice de desempenho $\left(\mathrm{PI}_{\text {total }}\right)$, que compreende a eficiência na utilização de um fóton absorvido pelo PSII para a redução dos aceptores finais de elétrons do PSI (Strasser et al., 2010).

$\mathrm{O}$ delineamento experimental utilizado foi o inteiramente casualizado, em esquema fatorial $2 \times 4$ (dois ambientes de luz, irradiância alta e moderada e 4 tratamentos de fertilização: $\mathbf{C}=$ tratamento controle sem $\mathrm{N}$; I = inoculadas e não fertilizadas com amônio; $\mathbf{I}+\mathbf{N H}_{4}^{+}=$inoculadas e fertilizadas com amônio; $\mathrm{NH}_{4}^{+}=$não inoculadas e fertilizadas com amônio) com 10 repetições $(n=10)$ para as análises de crescimento, área foliar específica, teores foliares de nitrogênio, fluorescência da clorofila $a$ e cinco repetições para as análises de matéria seca e trocas gasosas $(n=5)$. Os dados obtidos foram submetidos aos testes de normalidade de Lilliefors e homocedasticidade de Levene. Em casos de não atendimento aos pressupostos anteriores foram realizadas transformações com base nas funções raiz quadrada e logarítmica. Em seguida foram processadas análises de variância (Factorial ANOVA) e aplicado o teste de comparação de médias de Tukey $(p<0,05)$. O programa estatístico utilizado foi o Statistica 7.0.

\section{RESULTADOS E DISCUSSÃO}

O maior acúmulo de matéria seca foi observado em plantas fertilizadas com amônio em ambas as condições de luz. Sob alta irradiância, os valores de matéria seca total dos tratamentos $\mathrm{I}+\mathrm{NH}_{4}^{+}$e $\mathrm{NH}_{4}^{+}$ foram $116 \%$ e $89 \%$ superiores ao tratamento C, respectivamente (Figura 1). Em moderada irradiância, plantas que receberam somente amônio tiveram acúmulo de matéria seca cerca de $128 \%$ maior que o tratamento C. Entre os ambientes de luz, observou-se maior acúmulo de matéria seca da parte aérea em plantas do tratamento $\mathrm{NH}_{4}^{+}$sob moderada irradiância, e de raízes no tratamento $\mathrm{I}+\mathrm{NH}_{4}^{+}$sob alta irradiância (Figura 1).

$\mathrm{O}$ amônio pode ser tóxico em determinadas concentrações, interferindo diretamente no acúmulo de biomassa (Ariz et al., 2010; Cruz et al., 2011). No entanto, para I. edulis, a concentração de amônio de $5 \mathrm{mM}$ favoreceu o acúmulo de matéria seca e o aumento da nodulação (Omena-Garcia et al., 2011, 2015). É bem conhecida a contribuição dos esqueletos de carbono para a assimilação do amônio a aminoácidos (Roosta \& Schjoerring, 2008). Estudos conduzidos sob diferentes níveis de irradiância têm indicado que a maior intensidade de luz pode reduzir o efeito tóxico do amônio, uma vez que a captação de energia proporciona maior síntese de esqueletos de carbono destinados à assimilação de amônio e, dessa forma, maiores quantidades de nitrogênio são disponibilizadas, resultando no melhor desempenho dessas plantas quando submetidas à condição de estresse por alta irradiância (Zhu et al., 2000; Ariz et al., 2010, 2011).

Em plantas de I. edulis sob moderada irradiância foi mantido o fluxo de amônio para a raiz ao mesmo tempo em que ocorria o processo de fixação biológica. Contudo, como a fixação biológica é um dreno forte, isso pode ter gerado competição por energia para assimilar o amônio absorvido pelas raízes e a assimilação e produção de amônio na fixação biológica do nitrogênio, 

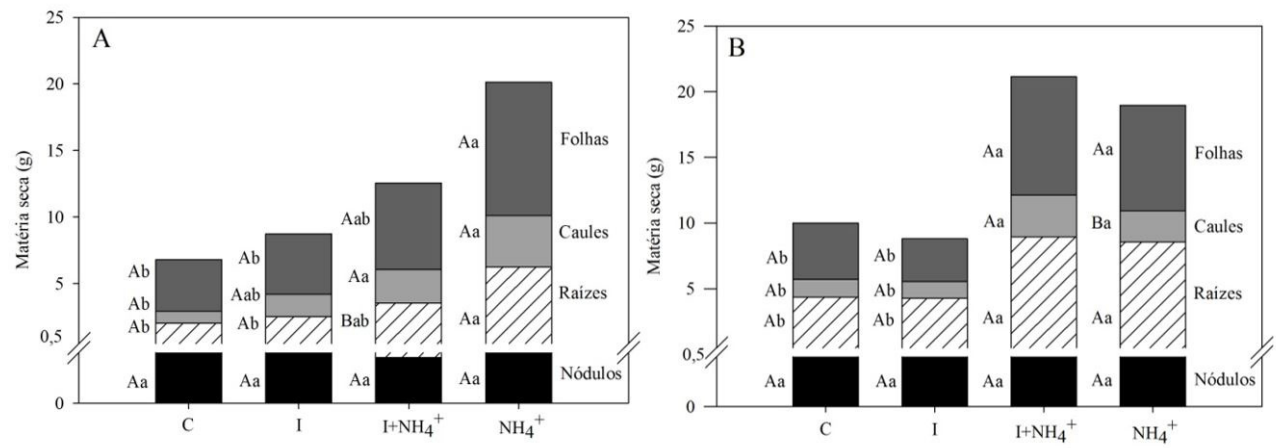

Figura 1. Matéria seca de diferentes partes das plantas de I. edulis inoculadas e não inoculadas submetidas a fertilização amoniacal em condições de irradiância moderada $(A)$ e alta $(B)(n=5)$. C = controle, sem inoculação e não fertilizadas com amônio; $\mathrm{I}=$ inoculadas e não fertilizadas com amônio; $\mathrm{I}+\mathrm{NH}_{4}^{+}=$inoculadas e fertilizadas com amônio; $\mathrm{NH}_{4}^{+}=$não inoculadas e fertilizadas com amônio; médias seguidas da mesma letra não diferem significativamente pelo teste Tukey $(p \geq 0,05)$; letras maiúsculas comparam as médias de matéria seca de cada parte das plantas no respectivo tratamento de fertilização entre diferentes condições de irradiância; letras minúsculas comparam a matéria seca das diferentes partes da planta entre tratamentos de fertilização na mesma condição de irradiância.

Figure 1. Dry matter of different components of $I$. edulis inoculated and non-inoculated subjected to ammonium fertilization under moderate (A) and high (B) irradiance. $\mathrm{C}=$ control, non-inoculation and not fertilized; $\mathrm{I}=$ inoculated and not fertilized; $\mathrm{I}+\mathrm{NH}_{4}{ }^{+}=$inoculated and fertilized; $\mathrm{NH}_{4}{ }^{+}=$non-inoculated and fertilized $(\mathrm{n}=5)$. Mean values followed by the same letters are not different by the Tukey test $(p \geq 0.05)$. Uppercase letters compare the average of dry matter to each fertilization treatments between different irradiance conditions. Lowercase letters compare fertilization treatments in similar irradiance condition.

uma vez que a fixação demanda muito mais energia do que a assimilação de amônio. Independentemente do tratamento, moderada ou alta irradiância, somente a inoculação não influenciou o crescimento das plantas. Ou seja, embora ela tenha vantagens adaptativas, por conseguir crescer sem $\mathrm{N}$ do ambiente, a planta não consegue atingir o potencial de crescimento, assim como observado em plantas fertilizadas com amônio.

A combinação da fertilização amoniacal (10 mM) e exposição a alta irradiância $\left(700 \mu \mathrm{mol}\right.$ de fótons $\left.\mathrm{m}^{-2} \mathrm{~s}^{-1}\right)$ proporcionou maior acúmulo de biomassa, incremento da razão raiz:parte aérea e das taxas fotossintéticas da espécie Triticum aestivum (Setién et al., 2013). Nesse caso, os autores sugerem que a limitação de esqueletos de carbono para a redução do amônio pode ter sido, em parte, a razão principal dos efeitos da toxicidade do amônio sobre o crescimento das plantas expostas a baixa irradiância $\left(300 \mu \mathrm{mol}\right.$ de fótons $\left.\mathrm{m}^{-2} \mathrm{~s}^{-1}\right)$.

Nas espécies arbóreas Acacia catechu, Bridelia retusa, Dalbergia sissoo, Lagerstroemia parviflora e Terminalia arjuna, o acúmulo de biomassa e as taxas de crescimento relativo foram superiores em plantas submetidas à condição de alta irradiância $\left(1.785 \mu \mathrm{mol} \mathrm{m}{ }^{-2} \mathrm{~s}^{-1}\right)$ e a maiores dosagens de nitrogênio
(60 kg e $120 \mathrm{~kg} \mathrm{~N} \mathrm{ha}^{-1}$ ). As diferentes condições de irradiância proporcionaram diferenças na alocação de biomassa, sendo que plantas sob moderada irradiância investiram predominantemente na expansão de área foliar, enquanto plantas expostas a alta irradiância aumentaram a produção de matéria seca foliar e a razão raiz:parte aérea (Tripathi \& Raghubanshi, 2014).

No presente estudo, plantas de I. edulis em ambas as condições de moderada e alta irradiância alcançaram maior valor de TCR-a, de TCR-d e de IGF sob fertilização amoniacal. Entre os tratamentos de fertilização, em condição de alta irradiância, a TCR-a $\mathrm{em} \mathrm{I}+\mathrm{NH}_{4}{ }^{+} \mathrm{e} \mathrm{NH}_{4}{ }^{+}$foi $133 \%$ superior ao C. A TCR-d de ambos os tratamentos $\left(\mathrm{I}+\mathrm{NH}_{4}^{+}\right.$e $\left.\mathrm{NH}_{4}^{+}\right)$foi $93 \%$ e $63 \%$ superior ao controle, ao passo que o IGF foi $171 \%$ e $128 \%$ mais elevado nos mesmos tratamentos (Tabela 1). A razão raiz:parte aérea foi maior em plantas sob alta irradiância, enquanto que os valores de área foliar específica (AFE) foram superiores para todos os tratamentos de fertilização na condição de moderada irradiância (Tabela 1).

A partição diferenciada de biomassa entre os ambientes de luz configura estratégias de aclimatação da espécie. $\mathrm{O}$ fato de as plantas expostas à alta irradiância 
Tabela 1. Taxas de crescimento relativo em altura (TCR-a) e diâmetro (TCR-d), índice de ganho foliar (IGF) $(\mathrm{n}=10)$, razão raiz:parte aérea $(\mathrm{R} / \mathrm{PA})$, área foliar específica $(\mathrm{AFE})$ e teor foliar de $\mathrm{N}$ total $(\mathrm{n}=5)$ de plantas jovens de I. edulis inoculadas e não inoculadas submetidas à fertilização amoniacal em diferentes condições de irradiância. $\mathrm{C}=$ controle, sem inoculação e não fertilizadas com amônio; I = inoculadas e não fertilizadas com amônio; $\mathrm{I}+\mathrm{NH}_{4}^{+}=$inoculadas e fertilizadas com amônio; $\mathrm{NH}_{4}^{+}=$não inoculadas e fertilizadas com amônio; os valores são médias \pm desvio-padrão.

Table 1. Relative growth rates in height and diameter, leaf gain index $(n=10)$, root: shoot ratio, specific leaf area and leaf $\mathrm{N}$ content $(\mathrm{n}=5)$ of young I. edulis plants inoculated and non-inoculated subjected to ammonium fertilization in different irradiance conditions. $\mathrm{C}=$ control, non-inoculation and not fertilized; $\mathrm{I}=$ inoculated and not fertilized; $\mathrm{I}+\mathrm{NH}_{4}{ }^{+}=$inoculated and fertilized; $\mathrm{NH}_{4}{ }^{+}=$non-inoculated and fertilized. Mean values \pm standard deviation (S.D.).

\begin{tabular}{|c|c|c|c|c|c|c|c|}
\hline Irradiância & Fertilização & $\begin{array}{c}\text { TCR-a } \\
\left(\mathrm{cm} \mathrm{cm}^{-1} \mathrm{mês}^{-1}\right)\end{array}$ & $\begin{array}{c}\text { TCR-d } \\
\left(\mathrm{mm} \mathrm{mm}^{-1} \mathrm{mês}^{-1}\right)\end{array}$ & $\begin{array}{l}\text { IGF } \\
(\%)\end{array}$ & R/PA & $\begin{array}{c}\text { AFE } \\
\left(\mathrm{cm}^{2} \mathrm{~g}^{-1}\right)\end{array}$ & $\begin{array}{c}\mathrm{N} \\
\left(\mathrm{g} \mathrm{kg}^{-1}\right)\end{array}$ \\
\hline \multirow{4}{*}{ Alta } & $\mathrm{C}$ & $0,11 \pm 0,04 \mathrm{Ab}$ & $0,18 \pm 0,05 \mathrm{Ab}$ & $94 \pm 68 \mathrm{Ab}$ & $0,70 \pm 0,11 \mathrm{Aa}$ & $210 \pm 46 \mathrm{Ba}$ & $26,3 \pm 3,5 \mathrm{Aa}$ \\
\hline & I & $0,10 \pm 0,04 \mathrm{Bb}$ & $0,21 \pm 0,08 \mathrm{Ab}$ & $125 \pm 77 \mathrm{Ab}$ & $0,88 \pm 0,03 \mathrm{Aa}$ & $217 \pm 25 \mathrm{Ba}$ & $31,5 \pm 3,0 \mathrm{Aa}$ \\
\hline & $\mathrm{I}+\mathrm{NH}_{4}^{+}$ & $0,21 \pm 0,07 \mathrm{Aa}$ & $0,34 \pm 0,04 \mathrm{Aa}$ & $256 \pm 59 \mathrm{Aa}$ & $0,71 \pm 0,17 \mathrm{Aa}$ & $214 \pm 11 \mathrm{Ba}$ & $27,8 \pm 4,2 \mathrm{Aa}$ \\
\hline & $\mathrm{NH}_{4}^{+}$ & $0,23 \pm 0,05 \mathrm{Aa}$ & $0,29 \pm 0,02 \mathrm{Aa}$ & $216 \pm 64 \mathrm{Aa}$ & $0,78 \pm 0,14 \mathrm{Aa}$ & $223 \pm 22 \mathrm{Ba}$ & $24,6 \pm 2,5 \mathrm{Aa}$ \\
\hline \multirow{4}{*}{ Moderada } & C & $0,13 \pm 0,02 \mathrm{Ab}$ & $0,18 \pm 0,02 \mathrm{Aab}$ & $95 \pm 30 \mathrm{Aa}$ & $0,38 \pm 0,09 \mathrm{Ba}$ & $320 \pm 45 \mathrm{Aa}$ & $30,2 \pm 4,9 \mathrm{Aa}$ \\
\hline & I & $0,22 \pm 0,07 \mathrm{Aab}$ & $0,16 \pm 0,07 \mathrm{Ab}$ & $111 \pm 25 \mathrm{Aa}$ & $0,41 \pm 0,14 \mathrm{Ba}$ & $326 \pm 29 \mathrm{Aa}$ & $36,7 \pm 1,9 \mathrm{Aa}$ \\
\hline & $\mathrm{I}+\mathrm{NH}_{4}^{+}$ & $0,26 \pm 0,1 \mathrm{Aa}$ & $0,26 \pm 0,04 \mathrm{Ba}$ & $135 \pm 40 \mathrm{Ba}$ & $0,37 \pm 0,05 \mathrm{Ba}$ & $307 \pm 38 \mathrm{Aa}$ & $34,8 \pm 1,9 \mathrm{Aa}$ \\
\hline & $\mathrm{NH}_{4}^{+}$ & $0,29 \pm 0,08 \mathrm{Aa}$ & $0,24 \pm 0,06 \mathrm{Aa}$ & $157 \pm 66 \mathrm{Aa}$ & $0,42 \pm 0,04 \mathrm{Ba}$ & $340 \pm 37 \mathrm{Aa}$ & $32,7 \pm 4,2 \mathrm{Aa}$ \\
\hline
\end{tabular}

Médias seguidas da mesma letra não diferem significativamente pelo teste Tukey ( $p \geq 0,05$ ); letras maiúsculas comparam os tratamentos de fertilização nas diferentes condições de irradiância e letras minúsculas comparam os tratamentos de fertilização na mesma condição de irradiância.

apresentarem maior razão raiz:parte aérea com maior investimento em biomassa radicular pode estar relacionado à maior demanda para absorção de água nesse tratamento, ao passo que a maior alocação de carbono na biomassa de folhas em plantas do ambiente de moderada irradiância contribuiu para o aumento da área de superfície foliar para a captação de luz (Gonçalves et al., 2012).

À semelhança deste estudo, a espécie Swietenia macrophylla também exibiu valores de AFE 75\% superiores na condição de moderada irradiância comparada ao ambiente de alta irradiância para Gonçalves et al. (2012). A AFE é uma variável importante na definição das estratégias de alocação de biomassa foliar, a qual reflete a área disponível para a captação de luz por unidade de fotoassimilados investidos nas folhas (Evans \& Poorter, 2001; Ferreira et al., 2013). Dessa forma, folhas expostas à moderada irradiância são mais finas, com menores concentrações de enzimas fotossintéticas por unidade de área, enquanto plantas crescendo sob alta irradiância geralmente têm folhas mais espessas com menor AFE (Perez-Harguindeguy et al., 2013).

Em condições de moderada irradiância, maiores valores de AFE estão, geralmente, relacionados às alterações morfoanatômicas que ocorrem nos compartimentos foliares, podendo ser observadas cutículas e epidermes mais delgadas. Também se verificam menor espessura do mesofilo e menor proporção de parênquima paliçádico, assim como de tecidos vasculares e de tecidos de sustentação, promovendo-se maior proporção de espaços intercelulares e menor densidade estomática naquelas plantas que crescem em regime de sombreamento (Berlyn \& Cho, 2000).

De modo geral, os valores absolutos para os teores foliares de $\mathrm{N}$ são em média $22 \%$ maiores nas plantas sob irradiância moderada. Nas plantas fertilizadas com amônio $\left(\mathrm{I}+\mathrm{NH}_{4}^{+}\right.$e $\left.\mathrm{NH}_{4}^{+}\right)$sob irradiância moderada, os valores são 25\% e 33\% superiores aos das plantas sob alta irradiância, respectivamente (Tabela 1). Porém não foram observadas diferenças estatísticas, o que pode estar relacionado ao alto desvio padrão das amostras em cada tratamento. Ademais, considerando-se que as análises foram realizadas apenas em folhas maduras, não se verificando o teor de $\mathrm{N}$ nos demais estádios fenológicos do desenvolvimento foliar (folhas novas e velhas) e sabendo-se das mudanças fisiológicas nesses estágios, quando comparada com a fisiologia da folha completamente expandida, especialmente no que se refere a alta mobilidade do $\mathrm{N}$ e à distinção entre fonte e dreno foliar ao longo do crescimento e desenvolvimento da folha, pode-se 
atribuir a ausência de diferenças entre os tratamentos, em parte, à amostragem relacionada a fenologia foliar.

As diferenças no acúmulo de matéria seca e crescimento, com os maiores valores observados nos tratamentos $\mathrm{I}+\mathrm{NH}_{4}^{+}$e $\mathrm{NH}_{4}^{+}$, foram acompanhadas pelo desempenho fotossintético $\left(\mathrm{P}_{\mathrm{N}}\right)$ das plantas (Figura 2). Diferenças significativas entre as respostas das plantas sob fertilização amoniacal em relação ao controle foram observadas a partir do $21^{\circ}$ dia após o início do experimento, sugerindo que o fornecimento de amônio favoreceu a aclimatação à alta irradiância mediante o melhor desempenho fotoquímico das plantas, expresso pelos parâmetros de fluorescência da clorofila $a\left(\mathrm{~F}_{\mathrm{v}} / \mathrm{F}_{\mathrm{m}}\right.$ e $\left.\mathrm{PI}_{\text {total }}\right)$ (Figura 2$)$.

Os valores de $\mathrm{F}_{\mathrm{v}} / \mathrm{F}_{\mathrm{m}}$ indicaram redução acentuada no desempenho fotoquímico das plantas em pleno sol no $7^{\circ}$ dia após o início do experimento. Em seguida, após 14 dias de experimentação pôde-se observar a

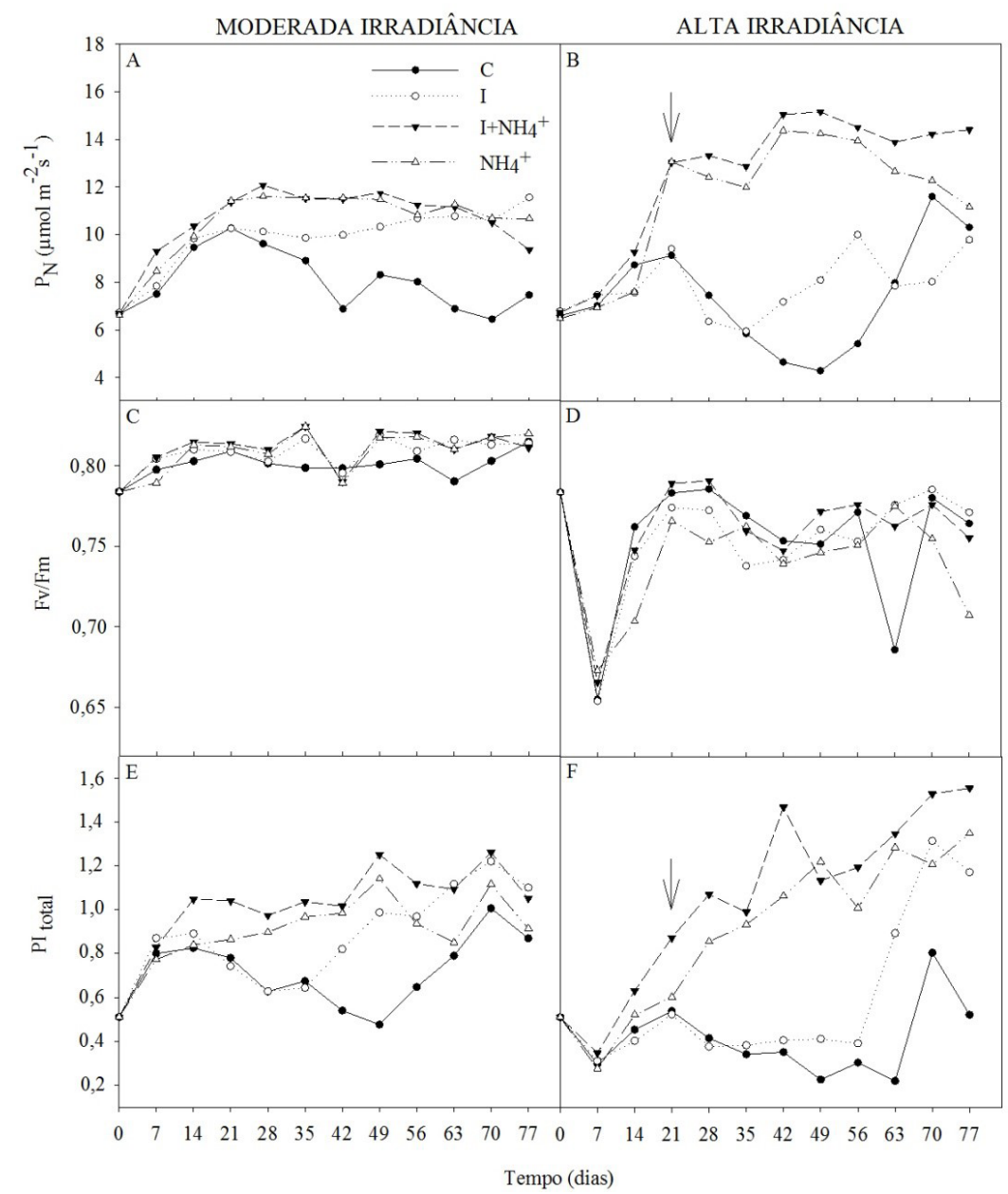

Figura 2. Fotossíntese $-\mathrm{P}_{\mathrm{N}}(\mathrm{A}, \mathrm{B})(\mathrm{n}=5)$, rendimento quântico máximo do PSII - $\mathrm{F}_{\mathrm{v}} / \mathrm{F}_{\mathrm{m}}(\mathrm{C}, \mathrm{D})$ e índice de desempenho - $\mathrm{PI}_{\text {total }}(\mathrm{E}, \mathrm{F})(\mathrm{n}=10)$ de plantas jovens de I. edulis inoculadas e não inoculadas submetidas à fertilização amoniacal em diferentes condições de irradiância. $\mathrm{C}=$ controle, sem inoculação e não fertilizadas com amônio; $\mathrm{I}=$ inoculadas e não fertilizadas com amônio; $\mathrm{I}+\mathrm{NH}_{4}^{+}$= inoculadas e fertilizadas com amônio; $\mathrm{NH}_{4}^{+}=$não inoculadas e fertilizadas com amônio; nas Figuras 2B, F, as setas indicam o início de diferenças significativas entre os tratamentos pelo teste de Tukey $(p<0,05)$.

Figure 2. Photosynthesis $-\mathrm{P}_{\mathrm{N}}(\mathrm{A}, \mathrm{B})(\mathrm{n}=5)$, maximum quantum yield of PSII $-\mathrm{F}_{\mathrm{v}} / \mathrm{F}_{\mathrm{m}}(\mathrm{C}, \mathrm{D})$ and performance index - $\mathrm{PI}_{\text {total }}(\mathrm{E}, \mathrm{F})(\mathrm{n}=10)$ of young I. edulis plants inoculated and non-inoculated subjected to ammonium fertilization in different irradiance conditions. $\mathrm{C}=$ control, non-inoculation and not fertilized; $\mathrm{I}=$ inoculated and not fertilized; $\mathrm{I}+\mathrm{NH}_{4}^{+}=$inoculated and fertilized; $\mathrm{NH}_{4}^{+}=$non-inoculated and fertilized. In the Figures $2 \mathrm{~B}, \mathrm{~F}$, the arrows indicate the onset of significant difference among treatments by Tukey test $(p<0.05)$. 
recuperação dessas plantas, que alcançaram o patamar das plantas sob irradiância moderada. Os valores de $\mathrm{PI}_{\text {total }}$, cujo parâmetro possibilita uma interpretação mais ampla da fase fotoquímica da fotossíntese (Strasser et al., 2010), demonstraram, por sua vez, que a retomada no desempenho fotoquímico em plantas expostas à alta irradiância foi mais proeminente sob fertilização amoniacal $\left(\mathrm{I}+\mathrm{NH}_{4}^{+}\right.$e $\left.\mathrm{NH}_{4}^{+}\right)$a partir do $21^{\circ}$ dia de experimentação (Figura 2).

As relações de causa e efeito entre o fornecimento de nitrogênio e os parâmetros de fluorescência da clorofila $a$ têm sido reportadas em outros estudos, os quais sugerem que esses parâmetros (e.g., $\mathrm{F}_{\mathrm{v}} / \mathrm{F}_{\mathrm{m}}, \mathrm{PI}_{\text {total }}$ ) podem ser fortemente afetados pela baixa disponibilidade de nitrogênio mineral (Nikiforou \& Manetas, 2011; Li et al., 2013). A deficiência de nitrogênio em plantas expostas a alta irradiância pode afetar tanto a eficiência de captação quanto de uso da energia luminosa (Ariz et al., 2010). Isso ocorre devido ao fato de grande parte do nitrogênio foliar ser destinado à síntese de proteínas e clorofilas dos complexos antenas e outros constituintes dos tilacóides, que permitem melhor rendimento na conversão da energia luminosa em energia química (ATP e NADPH) durante o processo fotoquímico (Eichelmann et al., 2005).

Em condições de campo, verificou-se que o estabelecimento inicial de plantas jovens de I. edulis em plantio sobre área degradada foi influenciado pela fertilização química e orgânica (Jaquetti et al., 2014). Nessa condição, o fornecimento adicional de nutrientes favoreceu o desempenho fotossintético e o melhor aproveitamento da energia mediante o investimento diferencial em moléculas de clorofila contribuindo para o maior crescimento das plantas.

Diante dos resultados descritos neste estudo, registra-se a efetiva participação da fertilização nitrogenada, na forma amoniacal, sobre a capacidade de aclimatação de I. edulis, espécie arbórea tropical, a condições contrastantes de irradiância, sendo essa resposta expressa, predominantemente, por meio do desempenho fotoquímico e da taxa de assimilação de carbono. A informação ecofuncional para ingá descrita neste artigo pode ser bem aproveitada em termos práticos, para fins de plantio, na medida em que estejam em discussão aspectos relacionados à seleção de espécies, espaçamento, demandas nutricionais e outras práticas silviculturais relacionadas aos fatores luz e fertilização nitrogenada.

\section{CONCLUSÃO}

A fertilização amoniacal potencializou a aclimatação de plantas jovens de $I$. edulis a alta irradiância, na medida em que os processos de captação, uso da energia e ganho de carbono foram otimizados nesse ambiente de luz, enquanto plantas jovens dessa Fabaceae arbórea submetidas a irradiância moderada investiram em estratégias de interceptação de energia (e.g., área foliar específica).

\section{STATUS DA SUBMISSÃO}

Recebido: 15 set., 2016

Aceito: 3 nov., 2016

\section{AUTOR(ES) PARA CORRESPONDÊNCIA}

\section{Marciel José Ferreira}

Departamento de Ciências Florestais, Universidade Federal do Amazonas - UFAM, Avenida General Rodrigo Octávio Jordão Ramos, 6200, CEP 69080-900, Manaus, AM, Brasil e-mail: mjf.ufam@gmail.com

\section{REFERÊNCIAS}

Ariz I, Artola E, Asensio AC, Cruchaga S, Aparicio-Tejo PM, Moran JF. High irradiance increase $\mathrm{NH}_{4}^{+}$tolerance in Pisum sativum: higher carbon and energy availability improve ion balance but not $\mathrm{N}$ assimilation. Journal of Plant Physiology 2011; 168(10): 1009-1015. PMid:21371777. http://dx.doi.org/10.1016/j.jplph.2010.11.022.

Ariz I, Asensio AC, Zamarreño AM, Garcia-Mina JM, Aparicio-Tejo PM, Moran JF. Changes in the C/N balance caused by increasing external ammonium concentrations are driven by carbon and energy availabilities during ammonium nutrition in pea plants: the key roles of asparagine synthetase and anaplerotic enzymes. Physiologia Plantarum 2013; 148(4): 522-537. PMid:23061733. http:// dx.doi.org/10.1111/j.1399-3054.2012.01712.x.

Ariz I, Esteban R, García-Plazaola JI, Becerril JM, Aparicio-Tejo PM, Moran JF. High irradiance induces photoprotective mechanisms and a positive effect on $\mathrm{NH}_{4}^{+}$stress in Pisum sativum L. Journal of Plant Physiology 2010; 167(13): 1038-1045. PMid:20434233. http://dx.doi. org/10.1016/j.jplph.2010.02.014. 
Berlyn GP, Cho J. Light, moisture, and nutrient use by plants. In: Ashton MS, Montagnini F, editors. The silvicultural basis for agroforestry systems. Boca Raton: CRC Press; 2000.

Bremner JM. Methods of soil analysis. Part 3: chemical methods. Madison: Soil Science Society of America/ American Society of Agronomy; 1996. Soil Science Society of America Book Series, n. 5.

Bugbee BG. Growth, analysis and yield components. In: Salisbury FB. Units, symbols, and terminology for plant physiology. Oxford: Oxford University Press; 1996.

Campoe OC, Iannelli C, Stape JL, Cook RL, Mendes JCT, Vivian R. Atlantic forest tree species responses to silvicultural practices in a degraded pasture restoration plantation: from leaf physiology to survival and initial growth. Forest Ecology and Management 2014; 313(1): 233-242. http://dx.doi.org/10.1016/j.foreco.2013.11.016.

Costa AC, Rezende-Silva SL, Megguer CA, Moura LMF, Rosa M, Silva AA. The effect of irradiance and water restriction on photosynthesis in Young jatobá-do-cerrado (Hymenaea stignocarpa) plants. Photosynthetica 2015; 53(1): 118-127. http://dx.doi.org/10.1007/s11099-015-0085-6.

Coste S, Roggy JC, Sonnier G, Dreyer E. Similar irradianceelicited plasticity of leaf traits in saplings of 12 tropical rainforest tree species with highly different leaf mass to area ratio. Functional Plant Biology 2010; 37(4): 342-355. http://dx.doi.org/10.1071/FP09119.

Cruz C, Domínguez-Valdivia MD, Aparicio-Tejo PM, Lamsfus C, Bio AMF, Martins-Loução MA et al. Intraspecific variation in pea responses to ammonium nutrition leads to different degrees of tolerance. Environmental and Experimental Botany 2011; 70(2-3): 233-243. http:// dx.doi.org/10.1016/j.envexpbot.2010.09.014.

Davanso VM, Souza LA, Medri ME, Pimenta JA, Bianchini E. Photosynthesis, growth and development of Tabebuia avellanedae Lor. Ex Griseb. (Bignoniaceae) in flooded soil. Brazilian Archives of Biology and Technology 2002; 45(3): 375-384. http://dx.doi.org/10.1590/S151689132002000300016 .

Eichelmann H, Oja V, Rasulov B, Padu E, Bichele I, Pettai $\mathrm{H}$ et al. Adjustment of leaf photosynthesis to shade in a natural canopy: reallocation of nitrogen. Plant, Cell \& Environment 2005; 28(3): 389-401. http://dx.doi. org/10.1111/j.1365-3040.2004.01275.x.

Evans JR, Poorter H. Photosynthetic acclimation of plants to growth irradiance: the relative importance of specific leaf area and nitrogen patitioning in maximizing carbon gain. Plant, Cell \& Environment 2001; 24(8): 755-767. http://dx.doi.org/10.1046/j.1365-3040.2001.00724.x.

Ferreira GA, Prado JAP Jr, Schiavini I, Melo I. Plastic responses in tree architecture and specific leaf area of Xylopia aromatica (Annonaceae): adaptations to environments with different light intensities. Brazilian
Journal of Botany 2013; 36(4): 279-283. http://dx.doi. org/10.1007/s40415-013-0035-0.

Gonçalves JFC, Santos UM Jr, Nina AR Jr, Chevreuil LR. Energetic flux and performace index in copaiba (Copaifera multijuga Hayne) and mahogany (Swietenia macrophylla King) seedlings grow under two irradiance environments. Brazilian Journal of Plant Physiology 2007; 19(3): 171-184. http://dx.doi.org/10.1590/S1677-04202007000300001.

Gonçalves JFC, Silva CEM, Justino GC, Nina Júnior AR. Efeito do ambiente de luz no crescimento de plantas jovens de mogno (Swietenia macrophylla King). Scientia Florestalis 2012; 40(95): 337-344.

Hoagland DR, Arnon DI. The water culture method for growing plants without soil. Berkeley: University of California, Agricultural Experimental Station; 1950. Circular n. 347.

Hoch L, Pokorny B, De Jong W. How successful is tree growing for smallholders in the Amazon? International Forestry Review 2009; 11(3): 299-310. http://dx.doi. org/10.1505/ifor.11.3.299.

Jaquetti RK, Gonçalves JFC, Ferraz JBS, Ferreira MJ, Santos UM Jr, Lacerda CF. Green fertilization enhances the photosynthetic performance and the growth of leguminous trees for restoration plantation in Central Amazon. American Journal of Plant Sciences 2014; 5(16): 2497-2508. http://dx.doi.org/10.4236/ajps.2014.516264.

Lambers $\mathrm{H}$, Poorter $\mathrm{H}$. Inherent variation in growth rate between higher plants: a search for physiological causes and ecological consequences. Advances in Ecological Research 1992; 23: 187-261. http://dx.doi.org/10.1016/ S0065-2504(08)60148-8.

Larbi A, Vázquez S, El-Jendoubi H, Msallem M, Abadía J, Abadía A et al. Canopy light heterogeneity drives leaf anatomical, eco-physiological, and photosynthetic changes in olive trees grown in a high-density plantation. Photosynthesis Research 2015; 123(2): 141-155. PMid:25344757. http:// dx.doi.org/10.1007/s11120-014-0052-2.

Leblanc HA, Mcgraw RL, Nygren P, Le Roux C. Neotropical legume tree Inga edulis forms N2-fixing symbiosis with fast-growing Bradyrhizobium strains. Plant and Soil 2005; 275(1-2): 123-133. http://dx.doi.org/10.1007/ s11104-005-0808-8.

Li D, Tian M, Cai J, Jiang D, Cao W, Dai T. Effects of low nitrogen supply on relationships between photosynthesis and nitrogen status at different leaf position in wheat seedlings. Plant Growth Regulation 2013; 70(3): 257-263. http://dx.doi.org/10.1007/s10725-013-9797-4.

Lojka B, Preininger D, Van Damme P, Rollo A, Banout J. Use of the Amazonian tree species Inga edulis for soil regeneration and weed control. Journal of Tropical Forest Science 2012; 24(1): 89-101.

Miyazawa M, Pavan MA, Muraoka T, Carmo CAFS, Mello WJ. Análise química de tecidos vegetais. In: Silva 
FC, editor. Manual de análise química de solos, plantas e fertilizantes. Brasília: EMBRAPA; 1999.

Nichols JD, Carpenter FL. Interplanting Inga edulis yields nitrogen benefits to Terminalia Amazonia. Forest Ecology and Management 2006; 233(2-3): 344-351. http://dx.doi. org/10.1016/j.foreco.2006.05.031.

Nikiforou C, Manetas Y. Inherent nitrogen deficiency in Pistacia lentiscus preferentially affects photosystem I: a seasonal field study. Functional Plant Biology 2011; 38(11): 848-855. http://dx.doi.org/10.1071/FP11040.

Omena-Garcia RP, Justino GC, Araújo VBF, Souza LAG, Camargos LS, Gonçalves JFC. Mineral of nitrogen associated changes in growth and xylem-N compounds in Amazonia legume tree. Journal of Plant Nutrition 2015; 38(4): 584595. http://dx.doi.org/10.1080/01904167.2014.957389.

Omena-Garcia RP, Justino GC, Soodek L, Gonçalves JFC. Mineral nitrogen affects nodulation and amino acid xylem transport in the Amazonian legume Inga edulis Mart. International Journal of Plant Physiology and Biochemistry 2011; 3(12): 3-6.

Onoda Y, Hikosaka K, Hirose T. Allocation of nitrogen to cell walls decreases photosynthetic nitrogen-use efficiency. Functional Ecology 2004; 18(3): 419-425. http://dx.doi. org/10.1111/j.0269-8463.2004.00847.x.

Perez-Harguindeguy N, Diaz S, Garnier E, Lavorel S, Poorter H, Jaureguiberry P et al. New handbook for standardised measurement of plant functional traits worldwide. Australian Journal of Botany 2013; 61(3): 167-234. http://dx.doi.org/10.1071/BT12225.

Ramalho JC, Pons TL, Groeneveld HW, Azinheira HG, Nunes MA. Photosynthetic acclimation to high light conditions in mature leaves of Coffea arabica L.: role of xanthophylls, quenching mechanisms and nitrogen nutrition. Australian Journal of Plant Physiology 2000; 27(1): 43-51.

Rooijen RV, Aarts MG, Harbiso J. Natural genetic variation for acclimation of photosynthetic light use efficiency to growth irradiance in Arabidopsis. Plant Physiology 2015; 167(4): 1412-1429. PMid:25670817. http://dx.doi. org/10.1104/pp.114.252239.

Roosta HR, Schjoerring K. Root carbon enrichment alleviates ammonium toxicity in cucumber plants. Journal of Plant Nutrition 2008; 31(5): 941-958. http://dx.doi. org/10.1080/01904160802043270.
Salomon E, Bar-Eyal L, Sharon S, Keren N. Balancing photosynthetic electron flow is critical for cyanobacterial acclimation to nitrogen limitation. Biochimica et Biophysica Acta 2013; 1827(3): 340-347. PMid:23201479. http:// dx.doi.org/10.1016/j.bbabio.2012.11.010.

Santiago WR, Vasconcelos SS, Kato OR, Bispo CJC, Rangel-Vasconcelos GT, Castellani DC. Nitrogênio mineral e microbiano do solo em sistemas agroflorestais com palma de óleo na Amazônia oriental. Acta Amazonica 2013; 43(4): 395-406. http://dx.doi.org/10.1590/S004459672013000400001.

Sarijeva G, Knapp M, Lichtenthaler HK. Differences in photosynthetic activity, chlorophyll and carotenoid levels, and in chlorophyll fluorescence parameters in green sun and shade leaves of Gingko and Fagus. Journal of Plant Physiology 2007; 164(1): 950-955. PMid:17074414. http:// dx.doi.org/10.1016/j.jplph.2006.09.002.

Scoffoni C, Kunkle J, Pasquet-Kok J, Vuong C, Patel AJ, Montgomery RA et al. Ligh-induced plasticity in leaf hydraulics, venation, anatomy, and gas exchange in ecologically diverse Hawaiian lobeliads. The New Phytologist 2015; 207(1): 43-58. PMid:25858142. http:// dx.doi.org/10.1111/nph.13346.

Setién I, Fuertes-Mendizabal T, González A, Aparicio-Tejo PM, González-Murua C, González-Moro MB et al. High irradiance improves ammonium tolerance in wheat plants by increasing $\mathrm{N}$ assimilation. Journal of Plant Physiology 2013; 170(8): 758-771. PMid:23485260. http://dx.doi. org/10.1016/j.jplph.2012.12.015.

Strasser RJ, Tsimilli-Michael M, Qiang S, Goltsev V. Simultaneous in vivo recording of prompt and delayed fluorescence and 820-nmreflection changes during drying and after rehydration of the resurrection plant Haberlea rhodopensis. Biochimica et Biophysica Acta 2010; 197(6-7): 1313-1326. PMid:20226756. http://dx.doi.org/10.1016/j. bbabio.2010.03.008.

Tripathi SN, Raghubanshi AS. Seedling growth of five tropical dry forest tree species in relation to light and nitrogen gradients. Journal of Plant Ecology 2014; 7(3): 250-263. http://dx.doi.org/10.1093/jpe/rtt026.

Vincent JM. A manual for the pratical study of root-nodule bacteria. Oxford: Blackwell Scientific; 1970.

Zhu Z, Gerendás J, Bendixen R, Schinner K, Tabrizi H, Sattelmacher B et al. Different tolerance to light stress in $\mathrm{NO}_{3}$ - and $\mathrm{NH}_{4}^{+}$grown Phaseolus vulgaris L. Plant Biology 2000; 5(2): 558-570. http://dx.doi.org/10.1055/s-2000-7498. 